\title{
Inequality in the Context Development Theories: Dependencia Theory and Washington Consensus
}

\author{
Jorge A. Charles-Coll \\ Universidad Autónoma de Tamaulipas, México \\ jacoll@uat.edu.mx
}

\begin{abstract}
This paper describes the characteristics of two important development theories: The Dependencia theory and the Washington consensus as a policy guideline for promoting development, and analyzes the role that inequality plays on their postulates according to the results from the previous analysis. This theoretical exercise is intended to illustrate the relevance of issues related to inequality on any set of policies that intend to generate development and discusses the fact that inequality does matter for growth due to the fact that distributional issues are embedded in the basic principles of economic systems. Any growth promoting policy should incorporate distributional arguments as an element that generates optimal conditions for economic growth by hampering the negative effects on the economy of high income inequality levels.
\end{abstract}

Keywords: Washington Consensus, Dependencia Theory, Income Inequality, Economic Growth

\section{Introduction}

It was not until the 90's when economist started paying serious attention to the role of income distribution on economic performance, until then it was just acquainted as a part of the economic periphery and as a political economy instrument ${ }^{1}$. The inverted-U hypothesis derived from the studies of Kuznets (1955) and developed later by Robinson (1976) was for decades the epitome of the relation between economic growth and income inequality. This proposition, based on a relatively extensive empirical study stated that in the path to development a country would most probably go through a period of inequality and capital concentration derived from the gradual movement of economic agents from a less productive activity (i.e., agriculture) to a more productive one (i.e., industry). This predicted effect of growth on the levels of inequality has been put into test by several studies during the last decade with contrasting results such as those of Deininger and Squire (1996) who concluded that the inverted-U theory only explains around $10 \%$ of the results when made on a country-specific study instead of a cross section study, this was consequent with the affirmations of Li and Zou (1998) who found that the Kuznets theory performs only with a cross section study carried out in a certain point in time instead of a specificcountry time survey. Currently, the debate has gone in to the other side of the equation, several studies have been made in order to find a possible relationship between income inequality and economic growth and the possible effects from the first to the latter, to mention some of them: Benerjee and Duflo (2003), Benabou (1996), Bertola (2000), Alesina and Rodik (1994), Perotti (1996), Deininger and Squire(1996), Persson and Tabellini (1994), Ferreira (1999) and Barro (1999).These studies have produced three main streams of thinking, first, the Political Economy model suggesting a relation between the variables resulting from redistributive policies, second, the Wealth Effect Argument, based on the assumption of imperfect financial markets and their effects on investment, and third, the Socio-Political Instability Channel which claims that inequality can create political and/or social instability that would disincentive investment and consequently growth.

This paper attempts to insert the above mentioned propositions into two important and representative development theories: Dependencia Theory and the Washington Consensus, as a theoretical exercise in order to identify which theoretical effect (if true) would they have on the postulates of each development theory and see if the predictions of this most influential theories are modified by the income-growth relationship. The objective is to explore on a theoretical level, the possible effects of inequality on the postulates of the Dependencia theory and the Washington consensus (as a set of policy recommendations for development), in the framework of the results from studies made over the effects of inequality on

${ }^{1}$ Although there are some earlier studies related to this topic, see: Adelman (1978) and Lindert and Williamson (1985). 
growth. This paper does not attempt to impose an effect on the predicted outcome of the theories but rather searches for the role that inequality plays on it and how do the different proposed channels by which income inequality works on the economic performance, could influence the performance of the postulates of these development theories. The reasons for selecting those specific theories are among others that they are contrastingly different and situated in different sides of the political and economical arena. (right and left \&orthodox and non-orthodox), the Washington consensus came to substitute the Dependencia theory as theory for development in most of Latin America, they are in totally opposite theoretical grounds, they where both stated originally to deal with underdevelopment in Latin America and then evolved to be applied for any poor country in the world.

\section{Inequality and the Dependencia Theory}

The Dependencia theory was the result of a series of researches made in the late 1950s under the sponsorship of the UNECLA (United Nations Economic Commission for Latin America) and its director at that time Raul Prebisch (1948-1962).They were trying to find the reasons to explain the profound underdevelopment that prevailed in the majority of the Latin American countries at that time and since several decades before. The result of this studies and others made by Theotonio Dos Santos, F.H. Cardoso and EnzoFaleto among others, were a series of postulates that later became an explanation for underdevelopment in any country and that came to be known as the Teoria de la Dependencia (dependency theory). The authors found the cause of this situation as derived from the economic dominance from a group of developed countries that had created a state of continuous dependency over the underdeveloped countries via the terms of trade, the division of labor and other market mechanisms ${ }^{2}$. The main idea was that the international economic dynamics were not benefiting all equally, there was a group of developed countries, called core countries that profited at the expense of another bigger group of underdeveloped countries whose economy moved on the periphery of the world market and that provided to core the primary commodities, raw materials and cheap labor to produce manufactured goods that later would be sold back to them with higher prices, creating a vicious cycle and a constant state of debt and dependency.

According to this theory, the main commodity trade takes place among the core countries in any direction and because they have the technological and productive advantage, they control the markets while a periphery country would normally have one strong relation with a core country and a minimal economic interaction with other countries in the same situation. At the same time the dominating countries exerted influence on the economy of the dependant countries via the multinational companies and international commodity markets which they controlled, also, because of the constant stagnation, the productive entities in the periphery countries had to rely on external capital goods to move the economy, increasing by this the dependency from the core. On the other hand within the country there is a small elite composed by landowners, capitalists, wealth owners and big producers whose goals are in line with those from the core countries. They are the ones (together with multinational companies) who maintain the strong dominant/dependent relation; their wellbeing depends on maintaining that strong link. The Dependencia theory was basically a political-economical argument that explained the causes of the underdevelopment of Latin American countries, here a summary of the main arguments of the theory:

2It is important to distinguish between the different variants of this theory, three were the main versions of the development theory, we can classify them in:

a) The Neocolonial Dependence model, that claimed the dependency situation as the result of a long win-lose relation between rich and poor countries that dates back to colonial times.

b) The False-Paradigm model, assigns the cause for underdevelopment to the effects of applying economic policy models from rich countries in poor economies derived from a dissonance between the effects of the economic recipes of rich countries on underdeveloped countries. And finally:

c) The Dualistic-development thesis, affirming that underdevelopment is not a preceding phase for development and that there is a dual society that is part of the same system, rich and poor countries exist simultaneous and chronically, and societies can also shelter a dual economy.

During its times of dominance, several variants of the Dependencia theory were proposed, nonetheless this paper will only refer to the dependency theory in the context of the moderated and original school of Dependencia represented by Prebisch, Dos Santos and F.H. Cardoso among others due to the fact that it was the original proposal and has been always the mainstream reference for this school of thought. 
- Underdevelopment is externally induced and the development of a periphery country is subordinated to the economic performance of the dominant country.

- Developed countries exert control over markets due to their technological and industrial advantages.

- Low levels of specialization and reliance on foreign technology in LDC's.

- International Division of labor is the cause of poverty in LDC's.

- The economy of the Periphery relies on the production of a few primary commodities such as agriculture, mining, etc. not being able to develop a manufacture industry.

- The dependency link is maintained by small elite of capital owners and MNC's within the poor countries.

- Because of international division of labor there is a non specialized-low skilled labor force in LDC's.

- The status of Dependency has additional indirect effects on the dependant country such as declining levels of mortality resulting from imported health techniques from the core and increasing levels of population growth rates derived from underdevelopment and ignorance, creating by this a growth trap.

The first thing to see in order to find the effect that inequality has on the development prospects of a country in the context of the Dependencia theory(and according to the above discussed mechanisms)is to define if it can actually play a role. As we can observe in point No. 6 of the list of arguments, the dependency relation is maintained by a small elite who exploits the rest of the population on behalf of its own interests and those of the core capitalists., this implies a state of inequality if we remember that landowners, capitalists, wealth owners and big producers compose the elite; Cardoso and Faletto (1979) also refer to inequality in a dependent economy in the context of how the relation state-private enterprise allows it:

Dependent development occurs through frictions, accords, and alliances between the state and business enterprises. But this type of development also occurs because both the state and business enterprises pursue policies that form markets based on the concentration of incomes and on the social exclusion of majorities. (Cardoso \& Faletto1979, p. 26).

Summarizing point No.6 it is clear that on this regard inequality plays a critical role and it is foreseeable in this context that the higher the levels of inequality, the higher predominance of an elite that controls the wealth of a country. As we have seen in the different studies presented in the first part of this document, the implications of this inequality on growth in this framework can be several:

- If we take the path of those who find a negative link between inequality and growth we could argue that the statement on point No. 6 is enough to partially explain underdevelopment in those countries. When we recall the findings of increasing inequality as it fosters socio-political instability and this in turn discourages investment and growth. An illustration of this is the sentence that an increase in the socio-political instability index by one standard deviation causes a decrease in the share of investment in GDP of about 4 percentage points (Alesina and Perotti, 1996, page 12).

- On the other hand we can directly discard the influence of the proposal from Rodriguez (2000) of an effect of inequality on the possibility of implementing necessary economic reforms. Such hypothesis does not apply because according to Cardoso and Faletto (1979), in this framework of dependency there is an alliance between the state and the business sector that has in their interests the 'concentration of incomes' and the subsistence of the dependency. This means that in the first place there is no intention for such reforms and even if the levels of inequality and socio-political instability plunged for them, no reform would take place.

- Regarding the political economy argument for inequality it is clear that it could not work in the context of the Dependencia theory, if the state and the business sector share the same objectives then the case of redistribution through capital taxation is very unlikely.

- In contrast, the effects of inequality on point No. 6, according to the wealth effect arguments and in the perspective of a negative and constant effect of inequality on growth are evident: The high inequality combined with the assumption of imperfect credit markets should have a negative effect on the economy, allowing access to credit only for the elite class and strengthening by this the link with the core. Distinctively, we can define (according to Barro's, 1999 results) the effect that inequality would have in the economy depending on the income level of the country: If the GDP per capita is below a figure around $\$ 2000$ (1985 U.S. dollars), the economy would tend to stagnate and the opposite would occur as incomes cross the above mentioned level and credit markets develop, allowing an efficient allocation of capital even with high inequality, this is 
illustrated on table No.2. With a list of selected countries in ascendant order of GDP per capita, by comparing the growth rates of the countries with higher Gini coefficient we see a consistency (although very weak) with Barro's findings.

- Another interpretation from this perspective related to point No. 1 can be made after analyzing one of the characteristics of Dependencia described by Theotonio Dos Santos:

The relation of interdependence between two or more economies, and between these and world trade, assumes the form of dependence when some countries (the dominant ones) can expand and can be selfsustaining, while other countries (the dependent ones) can do this only as a reflection of that expansion, which can have either a positive or a negative effect on their immediate development (Dos Santos, 1970).

This statement in the context of Barro's findings would imply that for low income counties below the $\$ 2000 \mathrm{GDP} /$ capita, the only way of crossing this line would be an expansion of the economy of the core to which they are dependent. After crossing it the economy would start to experience the positive effects of inequality on growth predicted by Barro, however, because the Dependencia theory rejects the trickledown effects of growth ${ }^{3}$ the dependence link will grow stronger because inequality will probably persist at high rates. Inequality is immersing in point No. 8 by the effect that incomes have on the population growth of a country. In this case the dependent country is situated in the second phase of the Malthusian demographic transition principles ${ }^{4}$ in which there is a high rate of population growth resulting from increasing birth rates and decreasing death rates (resulting from the importation of medical techniques and technology from the core). The transition from one phase to another is believed to be related to some welfare indicators such as income levels, access to health care, illiteracy rates, etc. In this context the propensity for an individual to jump to the next phase increases as those welfare indicators are increased. The third and last phase is the most desirable with low death and birth rates. This is related to income redistribution given that inequality and its effects on the welfare indicators are responsible for having most of the population in the second phase. Redistribution would allow the society to shift to the third stage. This argument is confirmed by Perotti (1996) who found that increasing the income of the middle class has the effect of decreasing the birth rates within a country. It is important to remember that the Dependencia theory was stated initially to explain the underdevelopment of Latin American countries and latter became accepted as an explanation for underperformance in any country, nevertheless we must have present the empirical differences or Latin effect and the considerable changes in the effects of inequality that they would have in the context of the Dependencia theory.

\section{Inequality and the Washington Consensus}

As noticed before, this second theory is closely related to the previous one in that it was originally stated to address underdevelopment in Latin America. Whereas the original dependency theory analyzes the causes for the underdevelopment of Latin America, the Washington consensus was stated as a formal policy guideline for Latin American countries in order to promote growth. Regardless of this, they are greatly contradictory in that they lay in completely opposite theoretical terrains. In words of Kerner, the Washington consensus identifies the development strategy followed by most Latin American countries since the 1940's Industrialization based on import substitution (ISI) as the starting point of its problems, mainly inflation and stagnation (Kerner, 2000). After the debt crisis in 1982 when most Latin American economies where facing a terrible economic downturn, with increasing currency devaluation and soaring inflation rates, the International Monetary Fund played a big role in providing credit and assistance to the affected countries. These loans were accompanied by policy prescriptions that impelled for drastic changes in the economy structure. The essence of the new policies known as Neo-Liberalism featured among their prescriptions: a minimal function of the state in productive activities, privatization of SOE's and a complete free- market approach for international trade, all of this was to be implemented rapidly as a sort of shock-therapy.

In those years this and other dominant policy recommendations were summarized in what it came to be known as the Washington Consensus. John Williamson first coined the expression 'Washington consensus' in 1989 on a background paper for a conference from the Institute of International Economics,

\footnotetext{
${ }^{3}$ See Ferraro (2008, page 6)

${ }^{4}$ According to the Malthusian principles the phases of the transition principles are the following: 1) High fertility and high mortality rates; 2) High fertility and low mortality rates and; 3) Low fertility and mortality rates. See Ray (1998, page 302-303) or Todaro and Smith (2003, page 259-303).
} 
and was reviewed a few months later in a paper titled What Washington Means by Policy Reform, in Williamson (1989). The paper included a list of 10 policy recommendations that, according to Washington ${ }^{5}$ where at that time the optimal prescriptions for Latin American countries. The term has been subject to many critics and studies, especially of the specific significance of the ten commandments, and their relation with the Neo-Liberal policies so much promoted by Ronald Reagan and Margaret Thatcher during the 1980's and beginning of the 1990's. In this section, the postulates of the theory will be presented as they were originally stated by John Williamson and with the original definitions. Additionally, some other important points of view will be added to enrich the arguments and in order to search objectively for variations in their relation with the inequality-growth effects. The following table presents the ten-policy prescription contained in the original Washington consensus (Williamson, 2004):

\section{Table 1: The ten commandments of the Washington consensus}

1. Fiscal Discipline.

2. Redirection of public expenditure priorities

3. Tax reform

4. Interest rate liberalization.

5. A competitive Exchange rate.

6. Trade liberalization

7. Liberalization of FDI flows.

8. Privatization.

9. Deregulation

10. Secure property rights.
Large and sustained fiscal déficits contribute to inflation and capital flight. Therefore, governments should keep them to a minimum.

Towards fields with high economic returns and the potential to improve income distribution such as primary health care, primary education, and infrastructure.

The tax base should be broad and marginal tax rates should be moderate.

Domestic financial markets should determine a country's interest rates. Positive real interest rates discourage capital flight and increase savings.

Developing countries must adopt a competitive Exchange rate that will bolster exports by making them cheaper abroad.

Tariffs should be minimized and should never be applied toward inter-mediat egoods needed to produce exports.

Foreign investment can bring needed capital and skills and, therefore, should be encouraged.

Private industry operates more efficiently because managers either have a direct personal stake in the profits of an Enterprise or are accountable to those who do. State-owned Enterprise sought to be privatized.

In the sense of abolishing barriers to entry and exit. Excessive government regulation can promote corruption and discrimínate against smaller enterprises that have minimal Access to the higher reaches of the bureaucracy. Governments have to deregulate the economy.

Property rights must be enforced. Weak laws and poor judicial systems reduce incentives tosave and accumulate wealth.

Source: Williamson (1989)

After more than a decade of debates, studies and results observation, the policy prescriptions above mentioned have become more and more questioned for their necessary application on any poor country. Even though this paper does not intend to analyze the failures or virtues of the consensus, it is important to be aware of the facts. Most of the Latin American countries for which the Washington consensus was

\footnotetext{
${ }^{5}$ The definition of what Washington means in the context of this consensus is not clearly defined on the proposal, here the two main definitions that can be made for it:

a) The term includes the International Financial Institutions (such as World Bank and IMF) and the United States Treasury.

b) The policy makers and the economic authorities in the United States.
} 
originally created still experience underdevelopment. The facts are undeniable; during the period of dominance of the Washington consensus the performance of the Latin American economies did not improved significantly and in many cases it has decline. Following the description of the theory and its postulates we turn now to see which role inequality plays in the theory. We begin with policy prescription No. 2: Redirection of Public Expenditure. This point is the only one in which inequality is addressed directly, it proposes a shift of public resources from unproductive activities to ones that can give more contributions than burdens to the economy. According to the Washington institutions, this reallocation should benefit the most disadvantaged sectors of the population and help improve income distribution. Williamson includes in his list, specific recommendations over which activities should be prioritized in order to achieve those goals. He mentions: a) Primary Health; b) Primary Education; and c) Infrastructure. Points A and B have a clear relation with both economic growth and inequality. Most of the studies presented in the first part of this paper have included Health and Education (human capital) as variables for inequality measures. The policy recommendation is very specific in that it urges for a redirection of expenditure to primary education so we must differentiate between the relations of this level of education with inequality and growth and from other levels. First of all it has been proved that in general, growth rates are in a big proportion a reflection of the aggregate human capital stock ${ }^{6}$. However, it has also been found that different levels of education have different effects on growth. Barro (1996) affirms that improvements in secondary schooling have a stronger growth enhancing effects than primary or superior levels. On the other hand he found that primary education has strong negative effects on inequality while secondary levels have a minimum impact on inequality and superior levels have a strong positive influence on inequality ${ }^{7}$. If only primary education is improved, the result of this policy implementation is that, as primary education levels increase, inequality would tend to go down. If the policy is also implemented for promoting secondary education then there would be a simultaneous effect of increasing growth and decreasing inequality.

Additionally, a study by Castelló and Doménech (2002) finds also a very important relation between human capital inequality and growth. They made a cross-section study for 108 countries over five year intervals from a period of 40 years (1960-2000) and elaborated a Gini indicator for human capital inequality to use in their study. Their results found a negative effect of human capital inequality on economic growth rates, finding that Countries that in 1960 showed greater inequality in the distribution of education have experienced lower investment rates than countries which showed less inequality (Castelló and Doménech, 2002. p. 12). In this sense, the implementation of the policies proposed by point No.2 oriented to deal with human capital provision such as primary education should be oriented not only to provide good levels of education but to promote a good distribution of that education to the entire population in order to achieve additional growth enhancing results. A later study by Castelló-Climent (2004) proposed a triangular relationship between intergenerational human capital, life expectancy and growth, among other findings they highlight that a policy for guaranteeing a minimum compulsory level of education for some generations Castelló-Climent (2004) would reflect on higher life expectancy and on a predisposition to increase investment on human capital. This could also mean if we take Primary Health as a factor for increasing life expectancy, that the redirection of public expenditures (in the way the Washington consensus proposes) toward basic health would increase the propensity of individuals to invest in higher levels of human capital ${ }^{8}$.

All of these findings put together in the context of the prescriptions of the Washington consensus mean that:

\footnotetext{
${ }^{6}$ See Benabou (1996).

${ }^{7}$ Other interesting results regarding the effects of human capital on growth are the following:

- Growth is positively affected by the average years of attainment at the secondary and higher levels of adult males but the relation becomes insignificant when accounting for both male and female(Barro,1996).

- Countries with higher human capital also have lower fertility rates and higher ratios of physical investment to GDP. These results on growth, fertility and investment are consistent with recent theories of endogenous growth Barro (1991).

${ }^{8}$ Other relevant findings over the relation of human capital and inequality are those of Eicher and Garcia-Peñalosa (2001). On their study of the triangular relation between human capital, inequality and growth based solely on the variations of human capital and technological changes they found that the movements in the supply and demand for skilled labor determine the movements in inequality. At the same time, inequality levels (and movements) and the growth rate are highly determined by the aggregate human capital in the economy.
} 
- Improving primary education promotes lower levels of inequality, but does not have great effects on growth. If the improvement is constant and across generations it also encourages an increase in life expectancy.

- Increasing life expectancy via primary education or primary health provision raises the propensity of individuals to increase their investment in human capital.

- Focusing both on primary and secondary education would bring distributional and growth benefits.

Regarding point No. 3, the implementation of a Tax reform oriented to broadening the tax base and reducing marginal tax rates. We can conclude that implementing this policy measure could have positive effects both to economic growth rates as on income inequality (based on the Political economy arguments) if a prerequisite is fulfilled: the structure of the tax system must be progressive. This way a broadening of the tax base can provide more funds for income equalizing redistribution. Simultaneously reducing the tax burden for capital owners and enhancing growth. Unfortunately during the strong years of the Washington consensus the precondition of a progressive tax system was not accomplished, Williamson (2004) refers to this on his latest review of the polemic Washington consensus, here a fragment of that refection: The dominant form of tax reform was the introduction or extension of VAT, driven by a desire for a resilient, broad-based (thus relatively nondistortive) revenue source, in part to offset the loss of revenue occasioned by tariff reductions. The main problem with VAT is that it is regressive2 (Williamson, 2004, p. 5).

Finally we turn to the last commandment in the Table, point No. 10, Secure Property Rights, this point has two sides to be addressed:

- Property rights from the perspective of the degree of security that any asset has against external threats. This situation is highly related to the legal frameworks in the economy and the institutions that are obliged to protect such entitlements.

- The situation of having ones assets within the boundaries of the law and receiving the legal benefits from being a part of the formal structure of the economy.

For the first point we recall the results form Benabou (1996).On his model using the social instability argument he argues that inequality has negative effects on property rights protection through its negative influence on socio-political conflicts. At the same time this combination produces negative effects on investment and growth, however finding a stronger effect of property rights on growth. The policy actions of this last policy recommendation (when interpreted from this perspective) should imply actions either to protect property rights, such as strengthening of institutions and legal structures in order to prevent any threat to private assets or; to address the causes that originate the threats. In this second case, inequality should be a primary issue. Addressing distributive problems would reduce social discontents (according to the socio-political arguments) and the propensity to incur in those kinds of predatory actions that affect private property. The second interpretation for secure property rights implies a whole different set of policy measures. It entails an attempt to reduce the levels of economic informality in order to integrate all economic activities to the established economic apparatus and to make them participants of the fiscal responsibilities and benefits of this condition. Here the relation with inequality and growth lies in the context of the political economy arguments. A bigger tax base would provide more resources from capital taxation in the case of redistribution; additionally these new legal economic actors will gain easier access to credit from the financial sector. Some of the policy recommendations cannot escape to face such an important socio-economical issue as inequality; the effects of those policies on this matter and the influence of inequality on them can vary depending on the interpretation and on the chosen theoretical grounds.

\section{Discussion}

This paper explores on a theoretical level, the possible effects of inequality on the postulates of the Dependencia theory and the Washington consensus (as a set of policy recommendations for development) in the framework of the results from studies made over the effects of inequality on growth. Initially presenting a description of two very important and contrasting development theories that share the characteristic of having been created for addressing the underdevelopment problems in Latin America, the Dependencia theory as a radical, nevertheless coherent explanation for the never ending stagnation of the Latin America economies; and the Washington consensus as a set of policy prescriptions for governments to implement drastically in order to prop up growth. The findings are that inequality, when analyzed in the context of the policy actions of those development theories, can have important 
effects on their outcomes derived from the inequality-growth relation and through any of the arguments. After this the obliged final question is: what recommendations can we deduce for any future policy prescription? For this we need to realize that none of the mechanisms by which inequality relates to growth are exclusive to each other; this means that if the conditions are appropriate, exists the possibility of defining a set of variables that can either affect or promote growth through the predicted outcomes from the different studies made in the context of these mechanisms. This way, policies should be oriented toward addressing these variables in order to assure the predicted performance of the mechanisms. Finally, it must be clear that the affirmation: ultimately it is better to be unequally rich than equally poor (Oleksiy, 2003) should never be the case. This paper showed that many studies support the theory that directing policy actions towards reducing inequality can be growth enhancing. Any policymaker in the disjunctive of making decisions on this regard should have in mind not only the goal of achieving the highest economic performance, but also the option of a growth rate below the optimum but with a good distribution of income.

\section{Reference}

Adelman I. (1978). Redistribution before Growth - A strategy for developing Countries. Institute of Social Studies, 5(1), 160-176.

Alesina, A. \& Perotti, R. (1996). Income distribution, political instability, and investment. European Economic Review, 40(6), 1203-1228.

Alesina, A. \& Rodrik, D. (1994). Distributive politics and economic growth. Quarterly Journal of Economics, 109(2), 465-490.

Banerjee, A. V. \& Duflo, E. (2003). Inequality and growth: What can the data say? Journal of Economic Growth, 8(3), 267-299.

Barro, R. J. (1991). Economic growth in a cross section of countries. Quarterly Journal of Economics, 106(2), 407-443.

Barro, R. J. (1996). Democracy and growth. Journal of Economic Growth, 1(1), 1-27.

Barro, R. J. (1999). Inequality, Growth and Investment. NBER working paper 7038.

Benabou, R. (1996). Inequality and Growth. NBER working paper 5658.

Bertola, G. (2000). Macroeconomics of distribution and growth. In Atkinson, A. B., \& Bourguigon, F. (Eds.), Handbook of income distribution, 1, 477-540, Amsterdam: Elsevier.

Cardoso, F. H. \& Faleto, E. (1979). Dependency and Development in Latin America. University of California Press. Berkeley California.

Castelló-Climent, A. (2004). A Reassessment of the relationship between inequality and growth: What human capital inequality data say? InstitutoValenciano de Investigaciones Económicas, 2004-15.

Castelló A. \& Doménech, R. (2002). Human Capital Inequality and Economic Growth: Some New Evidence, Universidad de Valencia.

Deininger, K. \& Squire, L. (1996). A new data set measuring income inequality. World Bank Economic Review, 10(3), 565-591.

Dos Santos, T. (1970). The Structure of Dependence. American Economic Review, 60(2), 231-36

Drache, D. (2000). The Post Washington Consensus: The Market Disconnect and the Public Reconnect. Robarts Centre for Canadian Studies, 5(1) 1-33.

Eicher, T. \& Garcia-Peñalosa, C. (2001). Inequality and growth: the dual role of human capital in development. Journal of Development Economics, 66(1), 173-197.

Ferraro, V. (2008). Dependency Theory: an Introduction. The Development Economics Reader, 12(2), 5864.

Ferreira, F. (1999). Inequality and Economic Performance: A Brief Overview to Theories of Growth and Distribution, Text for World Bank's Web Site on Inequality, Poverty, and Socio-economic Performance.

Kerner, D. (2000). Washington Consensus: a theoretical Reappraisal, Prepared for delivery at the 2000 meeting of the Latin American Studies Association, Universidad de Buenos Aires.

Kuznets, S. (1955). Economic Growth and Income Inequality. American Economic Review, 45(1), 1-28.

Li, H. \& Zou, H. F. (1998). Income inequality is not harmful for growth: Theory and evidence. Review of Development Economics, 2(3), 318-334.

Lindert, P. \& Williamson, J. (1985). Growth, Equality and History Explorations. Economic History, 22(1), 45-73.

Perotti, R. (1996). Growth, income distribution, and democracy: What the data say. Journal of Economic Growth, 1(2), 39.

Persson, T. \& Tabellini, G. (1994). Is Inequality Harmful for Growth? Theory and Evidence. American 
Economic Review, 84(3), 600-621.

Ray, D. (1998). Development Economics, Princeton University Press, Princeton New Jersey.

Robinson, S. (1976). A Note on the U-hypothesis Relating Income Inequality and Economic Development. American Economic Review, 66, 3, 473-440.

Rodriguez, F. (2000). Inequality, Economic Growth and Economic Performance. A Background Note for the World Development Report 2000.

Todaro, M. \& Smith, S. (2003). Economic Development, 8th edition, Addison Wesley, Essex U.K.

Williamson, J. (1989). The Washington Consensus as Policy Prescription for Development, Institute for International Economics. 